\title{
PENENTUAN LOKASI TOWER CRANE PADA PROYEK KONSTRUKSI BERBASIS SIMULASI
}

\author{
Gerwyn Persulessy ${ }^{1}$ dan Basuki Anondho² \\ ${ }^{1}$ Program Studi Sarjana Teknik Sipil, Universitas Tarumanagara, Jl. Letjen S. Parman No.1 Jakarta \\ gerwyn.325160127@stu.untar.ac.id \\ ${ }^{2}$ Program Studi Teknik Sipil, Universitas Tarumanagara, Jl. Letjen S. Parman No.1 Jakarta \\ basukia@ft.untar.ac.id
}

Masuk: 21-07-2020, revisi: 31-07-2020, diterima untuk diterbitkan: 02-11-2020

\begin{abstract}
Development of high-level building construction projects that require complex equipment that can be used in highlevel construction, equipment used to help complete construction projects called heavy equipment. One of the heavy equipment used in high-rise buildings is a tower crane. The use and layout of tower cranes can speed up the schedule and save on project costs. Therefore many methods have been developed to determine the tower crane layout. This study will discuss determining the location of tower cranes by discussing simulations. The location will be determined based on the site map data which is processed in the form of a geometric arrangement and tower crane data specifications. Location determination is done by comparing the total travel time of several simulated locations according to several different speed criteria in a construction project. Speed criteria are divided into four times the jib speed and trolley speed. Location of the location with the total travel time will be taken as the final result. Different speed criteria will make the total travel time change.
\end{abstract}

Keywords: Simulation model; location determination; construction project.

\begin{abstract}
ABSTRAK
Perkembangan proyek pembangunan gedung bertingkat tinggi yang semakin kompleks menyebabkan diperlukannya peralatan yang dapat mempermudah pembangunan gedung bertingkat, peralatan yang digunakan untuk membantu menyelesaikan tugas konstruksi disebut alat berat. Salah satu peralatan berat yang digunakan pada gedung bertingkat tinggi adalah tower crane. Penggunaan dan tata letak tower crane yang baik dapat mempercepat jadwal dan menghemat biaya proyek. Oleh karena itu banyak dikembangkan metode-metode untuk menentukan tata letak tower crane. Penelitian ini akan membahas penetapan letak lokasi tower crane dengan pendekatan simulasi. Letak lokasi akan ditetapkan berdasarkan data site map yang diolah dalam bentuk geometric layout dan data spesifikasi tower crane. Penetapan lokasi dilakukan dengan cara membandingkan total travel time dari beberapa lokasi yang disimulasi sesuai dengan beberapa kriteria kecepatan yang berbeda-beda pada suatu proyek konstruksi. Kriteria kecepatan terbagi menjadi empat berdasarkan besarnya kecepatan jib dan kecepatan trolley. Letak lokasi dengan total travel time terkecil akan diambil sebagai hasil akhir. Kriteria-kriteria kecepatan yang berbeda disimulasi akan membuat total travel time berubah.
\end{abstract}

Kata kunci: Model simulasi; penentuan lokasi; proyek konstruksi.

\section{PENDAhUluaN}

Perkembangan proyek pembangunan di Indonesia semakin pesat dan kompleks, membuat kita harus menyadari bagaimana kita menggunakan peralatan konstruksi. Peralatan konstruksi atau biasa disebut alat berat merupakan alat yang berguna untuk menyelesaikan tugas konstruksi (Sankairah et al, 2013). Salah satu peralatan yang paling sering kita lihat dan wajib digunakan untuk proyek konstruksi gedung bertingkat merupakan tower crane. Tower crane merupakan alat yang berguna memindahkan material baik secara horizontal dan vertikal. Lokasi tower crane sendiri memiliki peran penting dalam jadwal proyek, karena lokasi tower crane dapat menyebabkan perubahan jadwal seperti keterlambatan durasi proyek konstruksi yang juga akan mengakibatkan bengkaknya biaya (Hattab et al, 2017). Pemilihan lokasi tower crane yang baik juga bergantung pada beberapa parameter seperti kondisi lapangan, peraturan pemerintah, karakteristik tie crane, kapasitas, tinggi, jangkauan dan harga (Yeoh et al, 2017). Pengaplikasian simulasi sudah menghindarkan proyek dari banyak hal yang tidak diinginkan (AbouRizk et al, 2010), oleh karena itu simulasi akan digunakan untuk membantu memilih lokasi tower crane. Penetuan lokasi 
tower crane yang dibahas merupakan penentuan lokasi tower crane tunggal pada suatu proyek konstruksi yang cukup bisa dijangkau satu tower crane saja. Lokasi tower crane akan ditentukan dengan data-data tower crane dan site map yang nanti akan diolah menjadi geometric layout. Data-data itu akan dibawa kedalam pemodelan simulasi akan dibuat berdasarkan model matematika milik Zhang et al(1996) pada aplikasi powersim. Simulasi akan dilakukan selama beberapa kali untuk beberapa posisi tower crane. Semakin banyak simulasi lokasi yang kita lakukan maka semakin akurat hasil yang kita dapat. Seluruh hasil simulasi akan berbentuk total travel time, hasil total travel time akan dibandingkan satu sama lain untuk dipilih lokasi tower crane mana yang akan dipakai.

\section{METODE PENELITIAN}

\section{Geometric layout}

Geometric layout menerjemahkan site map kedalam diagram kartesius untuk dicari titik tengah dari semua titik supply dan titik demand. Untuk menjadi titik perwakilan dari titik tersebut. Namun sebelum menghitung titik tengah kita harus terlebih dahulu mengidentifikasi titik supply dan demand. Cara untuk mengidentifikasi dapat dilihat seperti gambar 1 dan gambar 2.

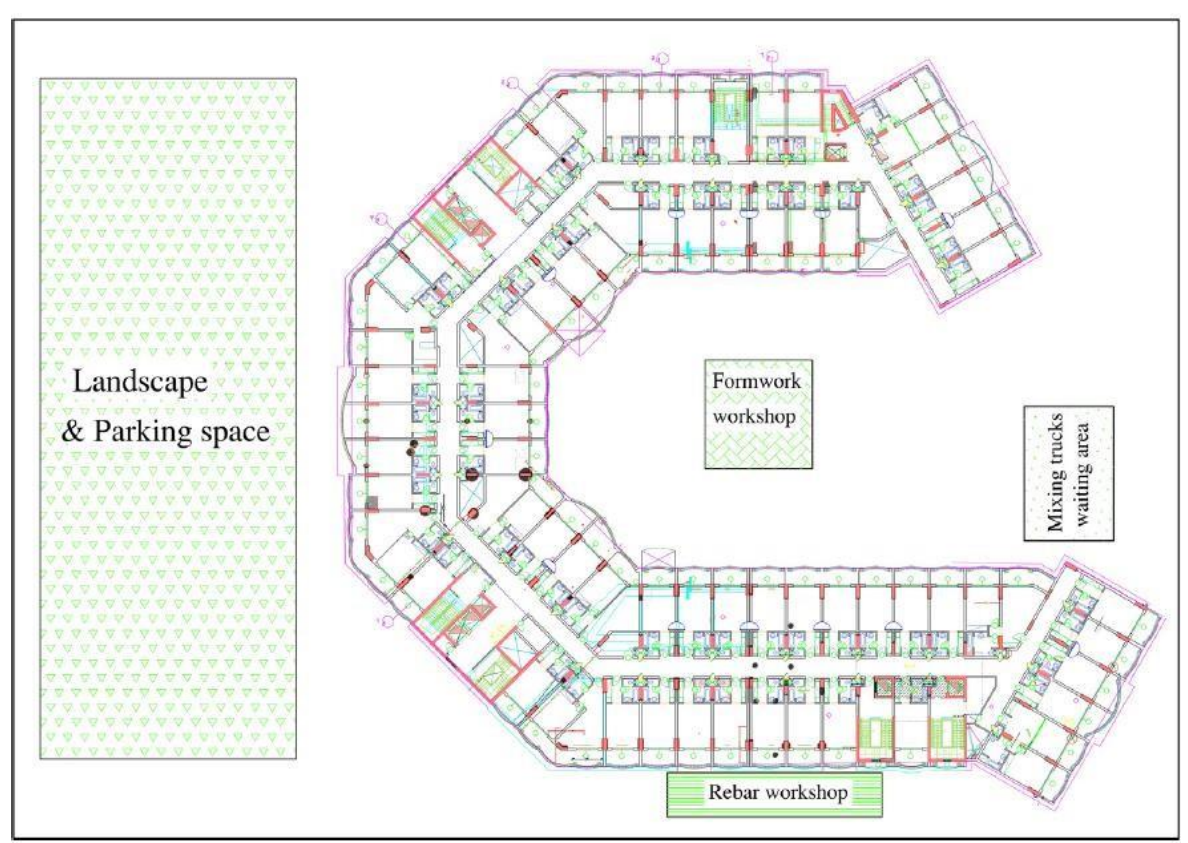

Gambar 1. Site map asli (Sumber: Abdelmegid et al, 2015)

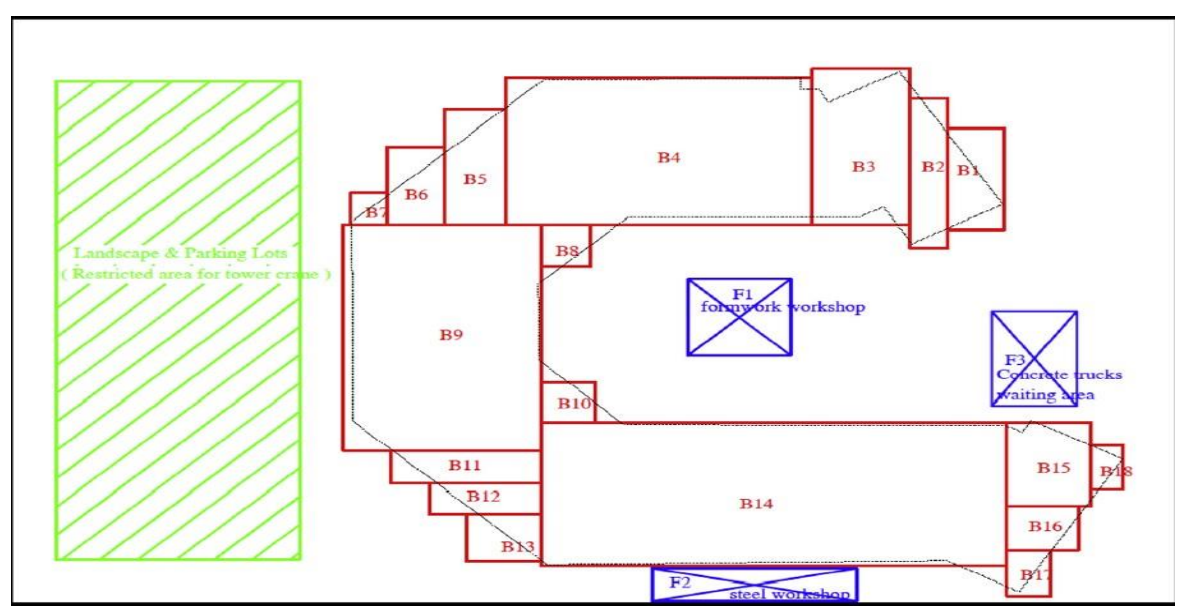

Gambar 2. Geometric layout (Sumber: Abdelmegid et al, 2015) 
Dapat dilihat disini site map dibentuk menjadi kotak-kotak dengan warna berbeda. Merah untuk titik demand dan biru untuk titik supply.

\section{Simulasi pada powersim}

Model merupakan gambar dari dunia nyata. Berikut merupakan contoh formulasi model untuk mempermudah proses pemahaman. Formulasi model dapat dilihat pada gambar 3.
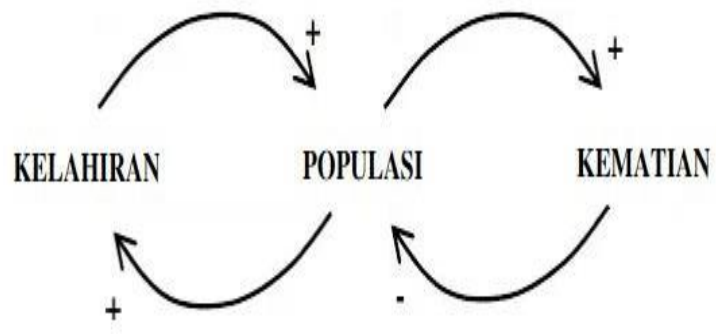

Gambar 3. Contoh formulasi model. (Sumber: Avianto, 2006)

Dari gambar diatas, dapat kita lihat populasi meningkat karena kelahiran dan berkurang karena kematian. Gambar ini juga mendeskripsikan semakin besar jumlah kelahiran, semakin besar juga jumlah kematian. Proses berikutnya adalah pemodelan kedalam powersim. Proses pemodelan pada powersim dapat dilihat pada gambar 4 .

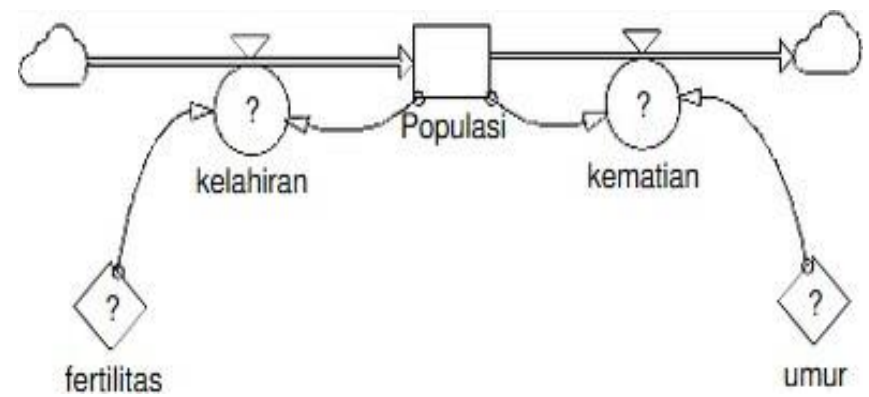

Gambar 4. Setelah ditambahkan constant. (Sumber: Avianto, 2006)

\section{Model matematika}

Model matematika yang digunakan sebagai berikut.

$$
\begin{aligned}
\rho_{i}= & \sqrt{(X D i-x)^{2}+(Y D i-y)^{2}} \\
\rho_{j}= & \sqrt{(X S j-x)^{2}+(Y S j-y)^{2}} \\
l_{i j}= & \sqrt{(X D i-X S j)^{2}+(Y D i-Y S j)^{2}} \\
& T a=\frac{\downarrow \rho_{i}-\rho_{j} \downarrow}{V a} \\
T \omega= & \frac{1}{\omega} \times A r c \cos \frac{l^{2}-\left(\rho_{i}^{2}+\rho_{j}^{2}\right)}{2 \times \rho_{i} \times \rho_{j}} \\
\text { TMij }= & \max (\mathrm{Ta}, \mathrm{T} \omega)+\min (\mathrm{Ta}, \mathrm{T} \omega) \times \alpha
\end{aligned}
$$


dengan $\mathrm{x}, \mathrm{y}=$ tower crane loacation; $\mathrm{x}, \mathrm{y}=$ tower crane loacation; $\mathrm{xdi}, \mathrm{ydi}=$ demand location; $\mathrm{xsj}, \mathrm{ysj}=$ supply location; $\rho_{i}=$ Jarak antara crane dan demand; $\rho_{j}=$ Jarak antara crane dan supply; Ta $=$ trolley raidal movement time ( $\mathrm{min}) ; \mathrm{T} \omega=j i b$ slewing movement time $(\mathrm{min}) ; V a=$ trolley radial velocity $(\mathrm{m} / \mathrm{min}) ; \omega=j i b$ slewing velocity $(\mathrm{r} / \mathrm{min}) ; \alpha=$ operation manner of crane hook (between 0 to 1 )

Gambar Geometric coordinates dapat dillihat pada gambar 5

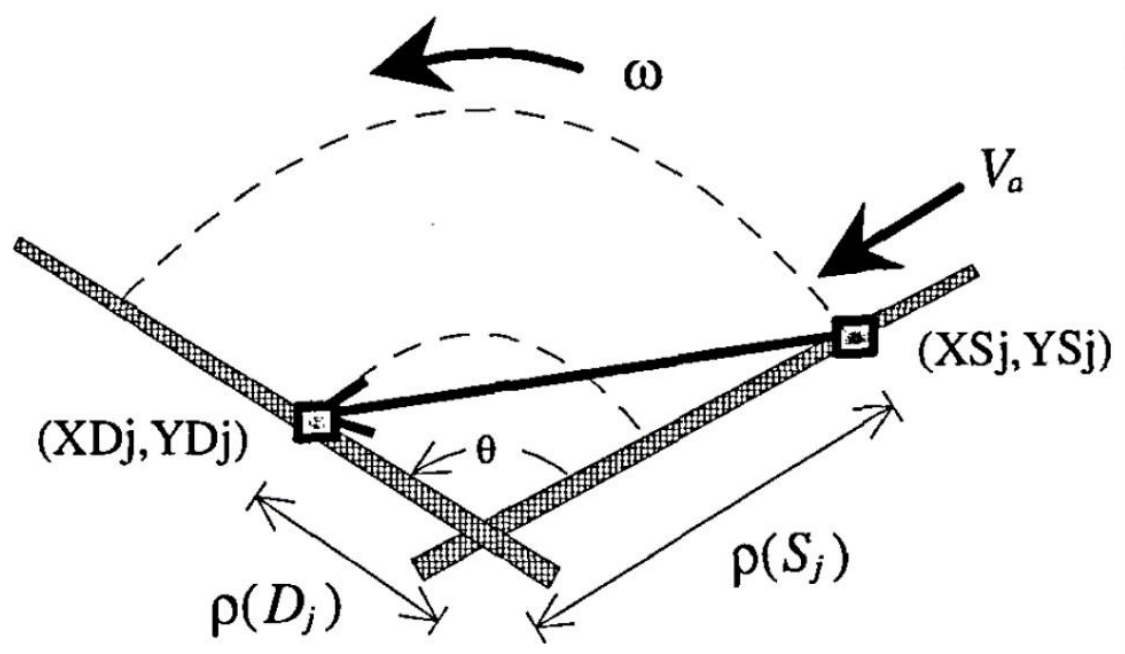

Gambar 5. Geometric coordinates (sumber: Zhang et al. 1996)

\section{HASIL DAN PEMBAHASAN}

Site map yang akan ditinjau merupakan site map yang didapat dari Nadoushani et al, 2016. Site map dapat dilihat pada gambar 6 .
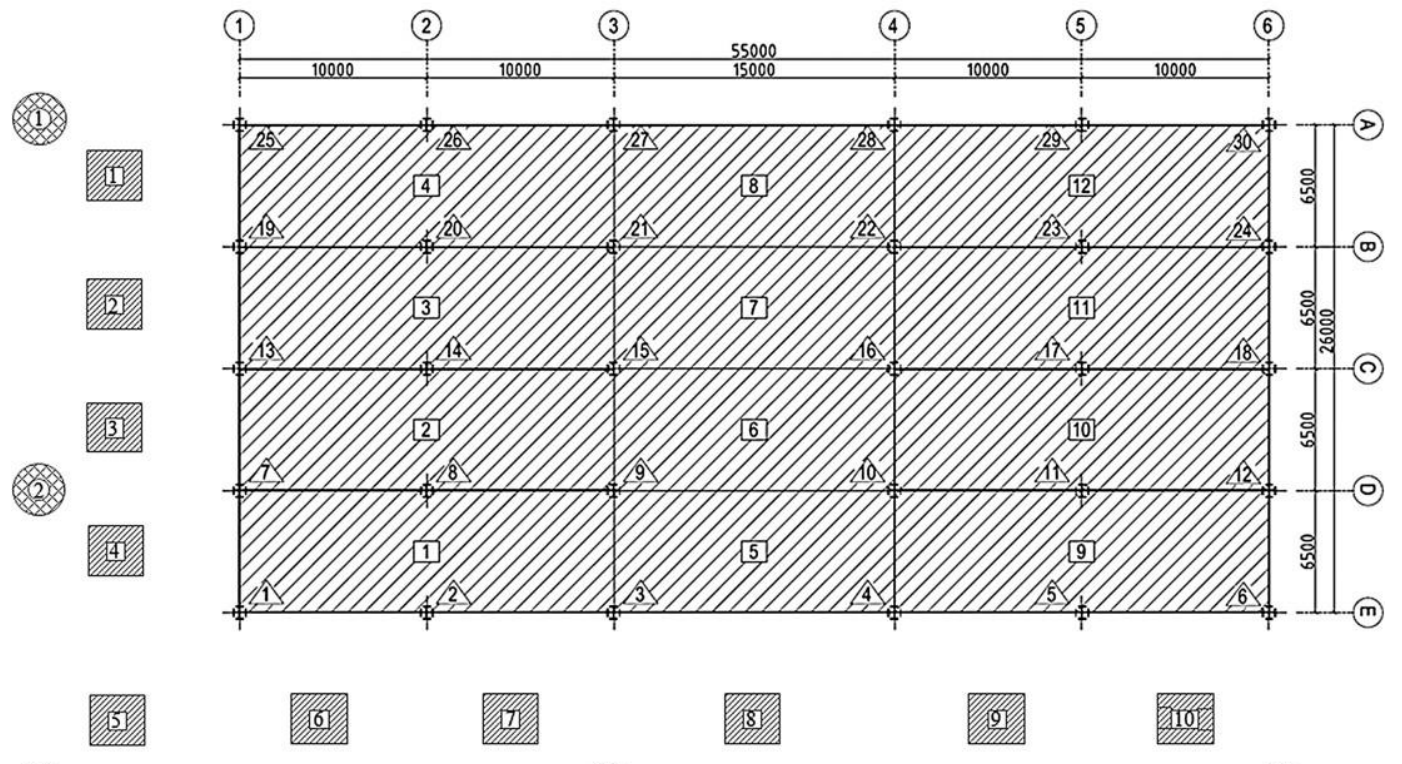

Gambar 6. Site map 
Site map kemudian diolah dengan geometric layout untuk mendapatkan titik supply dan demand. Simulasi akan dilakukan sebanyak sepulluh kali dengan kecepatan yang bervariasi. Seluruh lokasi yang diolah dapat dilihat pada tabel 1 .

Tabel .1 Geometric layout summary

\begin{tabular}{cccccc}
\hline \multicolumn{2}{c}{ Crane Location } & \multicolumn{2}{c}{ Supply } & \multicolumn{2}{c}{ Demand } \\
\hline $\mathrm{x}$ & $\mathrm{y}$ & $\mathrm{x}$ & $\mathrm{y}$ & $\mathrm{x}$ & $\mathrm{y}$ \\
\hline 45827 & 48773 & 59390 & 22900 & 82500 & 39000 \\
45957 & 42967 & 59390 & 22900 & 82500 & 39000 \\
45957 & 35880 & 59390 & 22900 & 82500 & 39000 \\
45618 & 27125 & 59390 & 22900 & 82500 & 39000 \\
45618 & 17444 & 59390 & 22900 & 82500 & 39000 \\
57834 & 18071 & 59390 & 22900 & 82500 & 39000 \\
69911 & 17863 & 59390 & 22900 & 82500 & 39000 \\
82474 & 18045 & 59390 & 22900 & 82500 & 39000 \\
96808 & 18045 & 59390 & 22900 & 82500 & 39000 \\
106561 & 18045 & 59390 & 22900 & 82500 & 39000 \\
\hline
\end{tabular}

Setelah itu hasil lokasi dapat di-input kedalam pemodelan simulasi yang sudah dibuat pada aplikasi powersim seperti pada gambar 7 .

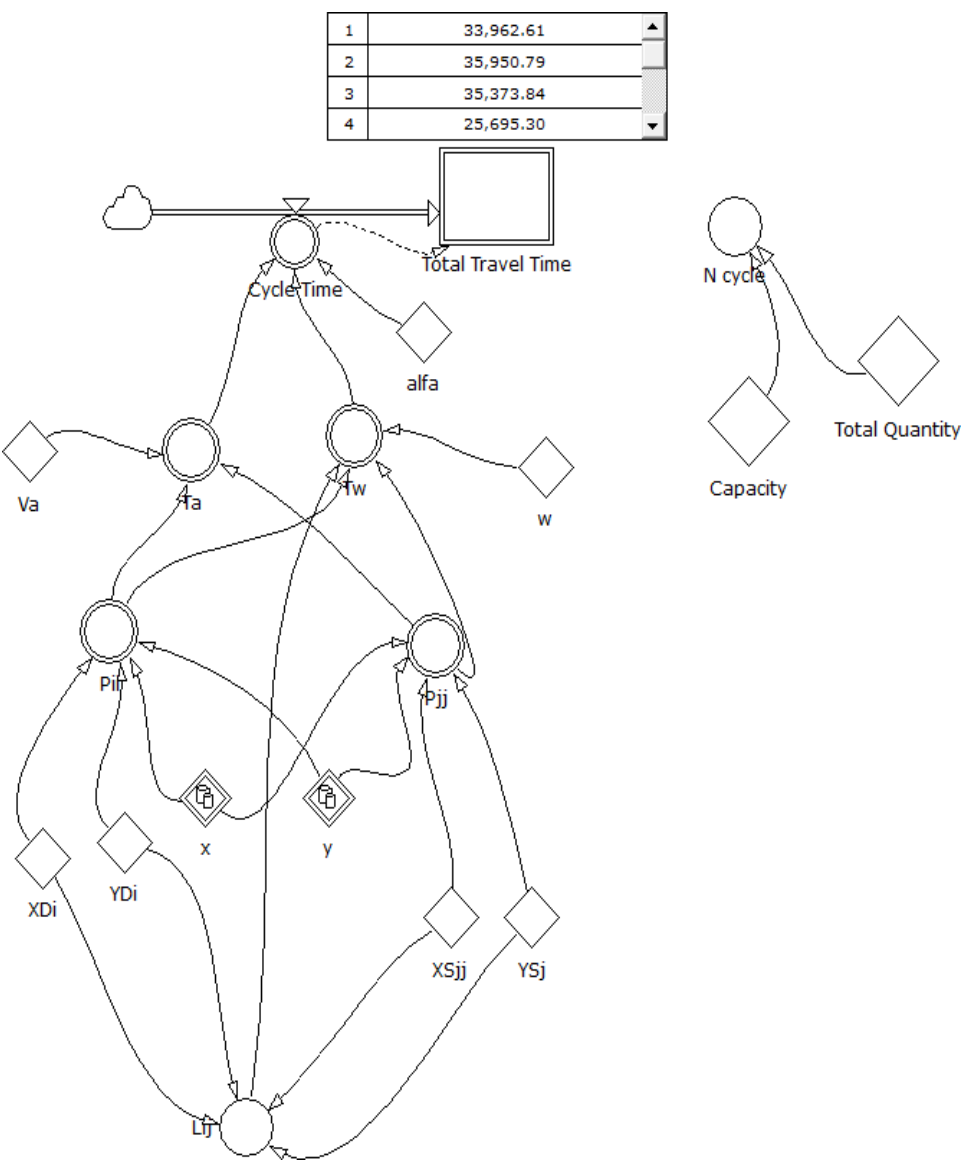

Gambar 7. Pemodelan Total travel time pada program powersim 
Pemodelan ini bertujuan membuat simulasi dari lokasi awal tower crane sampai pada total travel time dihitung, total travel time didapat dari dua variabel yaitu total repetisi dan cycle time. Diawali dengan input lokasi supply, demand dan lokasi tower crane yang akan disimulasi dengan input data-data geometric layout kita dapat menghitung cycle time, setelah itu dari input data kuantitas barang yang akan dipindahkan dan spesifikasi tower crane akan didapatkan total repetisi tower crane bergerak, dengan dua variabel tersebut maka total travel time maka total travel time dapat ditentukan dan dapat dibandingkan setelah disimulasi.

Pemodelan dilakukan berdasarkan model matematika yang dipakai. Pengujian dilakukan dengan 4 kriteria kecepatan. Berikut merupakan hasil simulasi dari 4 kriteria tersebut:

1. Va dan $\omega$ terlambat.

Hasil simulasi kriteria pertama dapat dilihat pada tabel 2.

Tabel 2. Hasil simulasi kriteria 1 dalam bentuk tabel

\begin{tabular}{cccc}
\hline \multicolumn{2}{c}{ Crane Location } & Total Travel Time (menit). & Total Travel Time (hari). \\
\multicolumn{1}{c}{$\mathrm{x}$} & $\mathrm{y}$ & & \\
\hline 45827 & 48773 & 203331,6641 & 141,2025445 \\
45957 & 42967 & 215104,5367 & 149,3781505 \\
45957 & 35880 & 211435,7555 & 146,8303858 \\
45618 & 27125 & 153148,409 & 106,3530618 \\
45618 & 17444 & 42378,51947 & 29,42952741 \\
57834 & 18071 & 140633,2392 & 97,66197164 \\
69911 & 17863 & 407342,5382 & 282,8767626 \\
82474 & 18045 & 333045,6796 & 231,281722 \\
96808 & 18045 & 207725,2338 & 144,2536346 \\
106561 & 18045 & 152603,5955 & 105,9747191 \\
\hline
\end{tabular}

2. Va tercepat, $\omega$ terlambat.

Hasil simulasi kriteria kedua dapat dilihat pada tabel 3.

Tabel 3. Hasil simulasi kriteria 2 dalam bentuk tabel

\begin{tabular}{cccc}
\hline \multicolumn{2}{c}{ Crane Location } & Total Travel Time & Total Travel Time (hari). \\
x & y & 202060,588 & 140,3198528 \\
\hline 45827 & 48773 & 213270,7844 & 148,1047114 \\
45957 & 42967 & 208818,6304 & 145,0129378 \\
45957 & 35880 & 149608,6082 & 103,8948668 \\
45618 & 27125 & 38320,29194 & 26,61131385 \\
45618 & 17444 & 136666,7514 & 94,90746623 \\
57834 & 18071 & 405461,1243 & 281,5702252 \\
69911 & 17863 & 332662,629 & 231,0157146 \\
82474 & 18045 & 205928,0961 & 143,0056223 \\
96808 & 18045 & 150347,5606 & 104,4080282 \\
\hline 106561 & 18045 & &
\end{tabular}

3. Va terlambat, $\omega$ tercepat.

Hasil simulasi kriteria kedua dapat dilihat pada tabel 4 . 
Tabel 4. Hasil simulasi kriteria 3 dalam bentuk tabel

\begin{tabular}{cccc}
\hline \multicolumn{2}{c}{ Crane Location } & Total Travel Time & Total Travel Time (hari). \\
$\mathrm{x}$ & $\mathrm{y}$ & 68907,06684 & 47,85212975 \\
\hline 45827 & 48773 & 73331,5142 & 50,92466264 \\
45957 & 42967 & 72804,91868 & 50,5589713 \\
45957 & 35880 & 54195,95929 & 37,63608284 \\
45618 & 27125 & 17733,48651 & 12,31492119 \\
45618 & 17444 & 50403,51331 & 35,0024398 \\
57834 & 18071 & 137453,214 & 95,45362081 \\
69911 & 17863 & 111355,716 & 77,33035836 \\
82474 & 18045 & 70839,20028 & 49,19388909 \\
96808 & 18045 & 52873,22944 & 36.71752045 \\
\hline 106561 & 18045 & &
\end{tabular}

4. Va dan $\omega$ yang tercepat.

Hasil simulasi kriteria kedua dapat dilihat pada tabel 5.

Tabel 5. Hasil simulasi kriteria 4 dalam bentuk tabel.

\begin{tabular}{cccc}
\hline \multicolumn{2}{c}{ Crane Location } & $\begin{array}{c}\text { Total Travel Time } \\
\text { (menit). }\end{array}$ & Total Travel Time (hari). \\
\hline 45827 & 48773 & 67635,9907 & 46,96943799 \\
45957 & 42967 & 71497,76197 & 49,65122359 \\
45957 & 35880 & 70187,79349 & 48,74152326 \\
45618 & 27125 & 50656,15847 & 35,17788782 \\
45618 & 17444 & 13675,25899 & 9,496707629 \\
57834 & 18071 & 46437,02552 & 32,24793439 \\
69911 & 17863 & 135571,8001 & 94,14708338 \\
82474 & 18045 & 110972,6654 & 77,06435094 \\
96808 & 18045 & 69042,06263 & 47,94587683 \\
106561 & 18045 & 50617,19462 & 35,1508296 \\
\hline
\end{tabular}

\section{KESIMPULAN DAN SARAN}

\section{Kesimpulan}

Penggunaan model simulasi untuk menentukan lokasi tower crane sudah pernah dilakukan pada masa lalu dengan berbagai macam model matematika. Penentuan lokasi tower crane juga banyak dihitung dengan metode-metode 
yang lain. Pada umumnya penentuan lokasi tower crane atau beberapa penelitan tentang optimasi lokasi tower crane dihitung berdasarkan waktu kerja proyek konstruksi.

Pemodelan simulasi ini menggunakan model matematika untuk menghitung slewing movement time, dan trolley movement time untuk memodelkan keseluruhan waktu tower crane bekerja selama satu proyek konstruksi. Kemudian pemodelan dilakukan sebanyak 10 kali untuk 10 lokasi tower crane.

Dari 10 lokasi tower crane yang disimulasi dalam berbagai kondisi kecepatan, posisi tower crane dengan total travel time terkecil didapat pada koordinat $(45618,17444)$ dan total travel time terbesar didapat pada koordinat (82474.18045). Dalam perhitungan juga, didapati bahwa pengaruh kecepatan jib tower crane lebih berpengaruh terhadap total travel time dari pada kecepatan trolley tower crane. Namun pengaruh kecepatan ini tidak mempengaruhi urutan total travel time tercepat, urutan ini dapat dilihat dari perbandingan hasil tabel. Urutan kecepatan total travel time tidak berubah walaupun total travel time berubah-ubah disetiap kriteria kecepatan.

\section{Saran}

Penelitian ini memliki kekurangan dan pembahasan yang kurang mendalam pada beberapa hal maka beberapa saran yang dapat diberikan untuk pengembangan peneletian selanjutnya adalah sebagai berikut.

1. Pemodelan simulasi ini hanya memperhitungkan total travel time dengan arah horizontal. Pengembangan selanjutnya dapat diperdalam dan dapat dimodelkan dengan arah vertikal juga.

2. Pemodelan ini hanya berlaku pada bangunan bertingkat yang membutuhkan satu tower crane saja. Pengembangan berikutnya dapat dimodelkan untuk beberapa tower crane sekaligus.

3. Penelitian ini hanya mensimulasi 10 lokasi tower crane. Untuk hasil yang lebih akurat, pemodelan smulasi dapat dilakukan untuk lebih bnayak lokasi lagi.

\section{DAFTAR PUSTAKA}

Justin K. W. Yeoh and David K. H. Chua. "Optimizing Crane Selection and Location for Multistage Construction Using a Four-Dimensional Set Cover Approach.” Journal of Construction Engineering and Management (2017).

Malak Al Hattab, Emile Zankoul, Farook R. Hamzeh. "Near-Real-Time Optimization of Overlapping Tower Crane Operations: A Model and Case Study.” Journal of Computing in Civil Engineering 31.4 (2017).

AbouRizk, Simaan. "Role of Simulation in Construction Engineering and Management." Journal of Construction Engineering and Management 136.10 (2010).

Avianto, Teten. Turitorial Powersim.WADE Group. Jakarta (2006).

Mohammed Adel Abdelmegid, Khaled Mohamed Shawki, Hesham Abdel-Khalek. "GA Optimization Model for Solving Tower Crane Location Problem in Construction Sites.” Alexandria Engineering Journal 54, 519-526 (2015).

M Sankariah; E Rambabu; C. Eswara Reddy. "Utilization of Tower Crane in Construction of Multi-Storeyed Buildings.” International Journal of Engineering Sciences \& Research Technology, 624-631 (2013).

P. Zhang, F.C. Harris and P.O. Olomolaiye. "A Computer-Based Model for Optimizing the Location of a Single Tower Crane.” Building Research and Information 24.2. (1996) 